\title{
Cytotoxic and Apoptotic Effects of Urticadioica Agglutinin on AGS Cells
}

\section{Fatma Zehra Çagıl, Zeynep Ulker Akal*and Lokman Alpsoy}

Fatih University, Science and Art Faculty, Biology Department, 34500, Istanbul, Turkey

\begin{abstract}
Urticadioica, stinging nettle, is a species of the Urticaceae family. U. dioica agglutinin (UDA) is a component of $U$. dioica, purified from its rhizomes. UDA which has lots of medicinal properties has been used as a folklore remedy since ancient times. In this study, we investigated the cytotoxic and apoptotic effects of one of a good representative ingredients of Urtica dioica agglutinin (UDA), at different concentrations $(1,5,10,20 \mu \mathrm{g} / \mathrm{ml})$ on AGS cancer cell line by carrying out WST-1 (cell proliferation), LDH (cytotoxicity), xCELLigence (real-time cell counter) and TUNEL (apoptosis) assays, respectively. According to our results different concentrations of UDA have anti-proliferative and apoptotic effects on AGS cell line after 48 hours. The RTCAassay indicated that lectin exhibited cytotoxicity, with an IC50 value $4.96 \mu \mathrm{g} / \mathrm{ml}$. Therefore, our current information regarding UDA confirms that UDA may be used in cancer therapeutic strategies as a primary cure in the future.
\end{abstract}

Keywords: Urtica dioica; Urtica dioica agglutinin; AGS; Cytotoxicty; Genotoxicty

\section{Introduction}

Urticadioica, conventionally stinging nettle, in plant kingdom it is a species of the Urticaceae. U. dioica is a perennial flowering herb with rhizomes, ovate leaves covered with bristly stinging hairs and have fleshy, drooping, serrated, roughly heart-shaped leaves [1]. Additionally, Urtica prefers wet, rich soil and tends to grow in large patches. The plant is distributed diversified regions of the world. It favours illuminated areas and nutrient rich soils to inhabit. $U$. dioica is endemic in the Europe and Asia [2]. It is outspreaded to North and South Africa, India, China, New Zealand, Australia, North and South America and endemic throughout Europe in particularly, It is very popular in Black Sea region of Turkey and another part of Turkey. All are considered therapeutically interchangeable. The seeds, rhizomes and leaves of $U$. dioica have been used in alternative medicine as a secondary remedy source in treatments of illnesses $[3,4]$. $U$. dioica is a slow-acting has other worthwhile contributions on health with the examples of therapeutics of eczema, anemia, inflammed joints, diabetes, rheumatoid arthritis, haemorrhage, hair loss due to anemia [5]. By way of addition, essences and some components of $U$. dioica have been utilized in cancer treatment strategies for many years. The leaf, flower, seed, and root of $U$. dioica are used differently and contain different chemical constituents [6].

Generally, it comprises glycoproteins, flavonoids, glycosides, polysaccharides, caffeoyl-esters; in specific formic acid, histamine, lectins, tannins, essential oils, vitamins A, B1, B2, C, K1, acetic acid [7]. Phenolic compounds, of the most important all, which are diverse and immense group of molecules that contain a plethora of dissimilar families of aromatic secondary metabolites in nettle [8]. On the other hand, in consequence of pharmacological proofs, one of the most strategic options in that respect to life promising cancer treatments are the lectins originated from $U$. dioica roots [9].

Plant lectins are a heterogeneous group of glycoproteins which all have in common the exclusive ability to recognize and tendency to bind specific sugar moieties [10]. For as much as phenolic compounds, rhizomes (roots) of stinging nettle contain considerable quantity of a lectin which exhibits carbohydrate-binding specificity for $\mathrm{N}$-acetylglucosamine oligomers [11].

Urtica dioica agglutinin is a small $(8.5 \mathrm{kDa})$ monomeric protein with high contents of glycine, cysteine, tryptophan and has a very low specific agglutination activity when it is compared to other plant lectins [11]. UDA is a quite stable protein consisting of a single polypeptide chain [12]. UDA with a small-molecular-weight, extracted from stinging nettle rhizomes, induces murine cell proliferation [13]. As reported previously, these proteins bind to specific carbohydrate residues on the lymphocyte membrane [14]. These protein structures induce a cascade of events at the end leading to cell activation processes, including cell proliferation, production of lymphokines, and cell differentiation [15]. Together with mentioned above, UDA since the name itself gives a hint that it agglutinates erythrocytes nonspecifically irrespective of blood group type and also induces the production of gamma interferon human lymphocytes [12]. Despite the fact that most well-characterized plant lectins, in particular those of legumes, as it may refer to the metabolism and physiological mission of these carbohydrate-binding proteins, the quantity of plant lectins extracted from the other parts of the plant has turned into a great interest [12]. Again, the question arises whether proteins with an entirely discrete configurations and sugar-binding specificity would accomplish alike in other words parallel physiological roles [10]. Hence, scope of this study is to investigate the cytotoxic and apoptotic effects of UDA on AGS cell line in vitro.

\section{Material and Methods}

All products used for cell culture (Dulbecco's Modified Eagle's Medium (DMEM), fetal bovine serum (FBS, $-20^{\circ} \mathrm{C}$ ), phosphate buffer saline (PBS), L-glutamine and penicillin-streptomycin (PS) were purchased from Biochrom AG (Mannheim, Germany, $+4^{\circ} \mathrm{C}$ ). Cell Proliferation Reagent (WST-1) kit, $L D H$ cytotoxicity detection, TUNEL kitswere purchased from Roche (Mannheim, Germany, $-20^{\circ} \mathrm{C}$ ). Pure and FITCH conjugated Urtica dioica agglutinin from stinging nettle, Ey Laboratories, (San Matea, CA, USA, $-20^{\circ} \mathrm{C}$ ) Cell death induced by the binding of lectin was examined in a human gastric adenocarcinoma cell line (AGS cells) in vitro. All other chemicals were of reagent grade.

*Corresponding author: Zeynep Ulker Akal, Fatih University, Science and Art Faculty, Biology Department, 34500, Buyukcekmece/lstanbul, Turkey, Tel: +90212-8663300/2020; E-mail: zulker@fatih.edu.tr

Received February 14, 2015; Accepted March 22, 2015; Published March 24 2015

Citation: Çagıl FZ, Akal ZU, Alpsoy L (2015) Cytotoxic and Apoptotic Effects of Urticadioica Agglutinin on AGS Cells. Med chem 5: 124-129. doi:10.4172/2161 0444.1000253

Copyright: $\odot 2015$ Çagıl FZ, et al. This is an open-access article distributed under the terms of the Creative Commons Attribution License, which permits unrestricted use, distribution, and reproduction in any medium, provided the original author and source are credited. 


\section{LDH activity assay}

According to the manufacturer instructions, Cytotoxicity Detection Kit (LDH; Roche) is used to measure the amount of lactate dehydrogenase (LDH)released by dead cells. The conversion of tetrazolium salt into a red formazan dye product was measured calorimetrically. For this assay, a positive control (PC), leading to $100 \%$ cytotoxicity by lysing the cells completely, was included in the assay. As a positive control (i.e., decreasing viability) $2 \%$ Triton X-100 solution in the assay medium, as proposed by the manufacturer was used. As a negative control (equivalent to normal viability) the cells were cultured without any substance in full medium.After preincubation of the cells, before addition of the test compounds at concentrations (UDA) 1, $5,10,20 \mu \mathrm{g} / \mathrm{ml}$, the growth medium was exchanged from medium containing 5\% FBS to medium containing only $1 \%$ FBS. For testing the released LDH activity, $100 \mu \mathrm{l}$ of culture medium was transferred to a new 96-well plate at 24 th and 48th hour. The reaction solutions of $100 \mu \mathrm{l}$ from the kit, containing the detection dye and the catalyst, were added to the wells and kept in the dark at room temperature for $30 \mathrm{~min}$ at $490 \mathrm{~nm}$ with $690 \mathrm{~nm}$ as a reference wavelength in an enzyme linked immunosorbent assay (ELISA) microplate reader (BioTek-Power Wave, Winooski, USA). A culture medium without cells was used as a blank. As for the other assays, background values from wells without cells were subtracted and average values for the six times calculated. Means +SD values are represented in Figure 1 cytotoxicity (\%) was then calculated according to the following equation:

Cytotoxicity $(\%)=($ experimental value - negative control $) /$ (positive control-negative control) x100

\section{Proliferation assay}

AGS cell line was seeded in triplicate at $1 \times 10^{4}$ cells/well to the 96 well plates in final volume of $100 \mu \mathrm{l} /$ well culture medium in a humidified atmosphere $\left(37^{\circ} \mathrm{C}, 5 \% \mathrm{CO}_{2}\right)$ for $24 \mathrm{~h}$ before the treatment. After that cell lines were exposure to the determined concentrations of Urtica dioica agglutinin (UDA) $1,5,10,20 \mu \mathrm{g} / \mathrm{ml}$. Cell proliferations was evaluated for AGS cell line at $24 \mathrm{~h}$ and $48 \mathrm{~h}$ were determined with the WST-1 cell proliferation assay (Roche). Cell Proliferation Reagent WST-1 was added in a $10 \mu \mathrm{l} /$ well volume. Cells were incubated for $4 \mathrm{~h}$

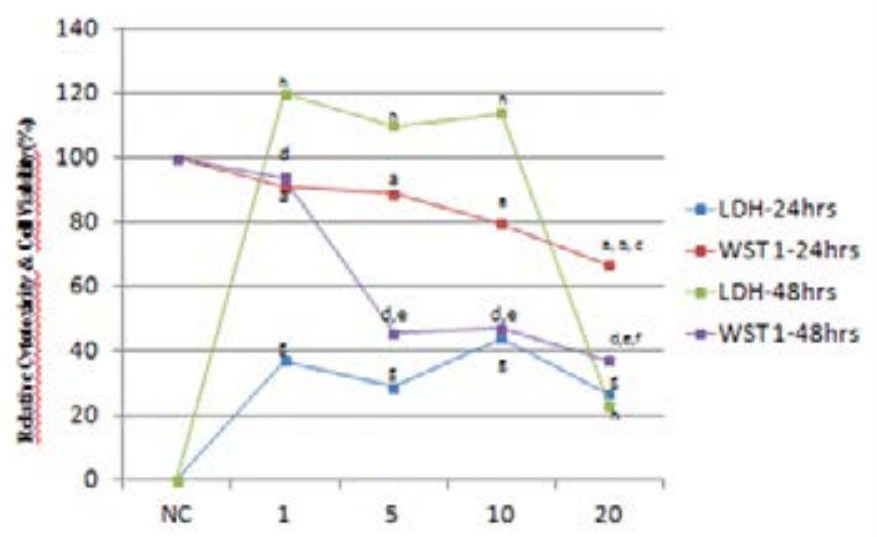

Figure 1: Results of LDH and WST-1 Assays. AGS cell line treated 24h and 48 $h$ at different concentrations of UDA. NC: Negative Control (Only medium with AGS cell line), 1, 5, 10, 20: UDA concentrations ( $\mu \mathrm{g} / \mathrm{ml})$. AGS WST-1 $\mathrm{p}^{\mathrm{a}} \leq 0.05$ compared with control group; $\mathrm{pb} \leq 0.05$ compared with Lectin- 1 group, $\mathrm{pc} \leq 0.05$ compared with Lectin- 5 group 24 hour; $\mathrm{p}^{\mathrm{d}} \leq 0.05$ compared with control group pe $\leq 0.05$ compared with Lectin-1 group, pf $\leq 0.05$ compared with Lectin-5 group, 48 hour. AGS LDH-24; $\mathrm{p}^{9} \leq 0.05$ compared with control group; AGS $\mathrm{LDH}-48 ; \mathrm{p}^{\mathrm{h}} \leq 0.05$ compared with control group; one way ANOVA test. in a humidified atmosphere $\left(37^{\circ} \mathrm{C}, 5 \% \mathrm{CO}_{2}\right)$. As a negative control (equivalent to normal viability) the cells were cultured without any substance in full medium. The samples absorbance was measured at $420 \mathrm{~nm}$ through ELISA reader.

\section{$\mathrm{x}$ CELLigence system for analyzing the cell proliferation}

AGS cell lines was grown and expanded in tissue-culture flasks. After reaching $75 \%$ confluence, the cell lines were washed with PBS, afterwards detached from the flasks by a short time treatment with trypsin/EDTA. Subsequently, $100 \mu \mathrm{l}$ of cell culture media at room temperature was added into each well of E-plate 96. After this the E-plate 96 was connected to the system and checked in the cell culture incubator for proper electrical-contacts and the background impedance was measured during 24s. The cell line was resuspended in cell culture medium and adjusted to 10.000 cells $/ \mathrm{ml}$ at the same time. $100 \mu \mathrm{l}$ of each cell suspension was added to the $50 \mu \mathrm{l}$ medium containing wells on E-plate 96, in order to determine the optimum cell concentration. After 30 minutes of incubation at room temperature, E-plate 96 was placed into the cell culture incubator. Finally, adhesion, growth and proliferation of the cells was monitored every $15 \mathrm{~min}$ for a period of up to $24 \mathrm{~h}$ via the incorporated sensor electrode arrays of the E-Plate 96 . The electrical impedance was measured by the RTCAintegrated software of the xCELLigence system (Roche) as a dimension less parameter termed CI. The proliferation, attachment and spreading of the cells was monitored for each 15 minutes by the xCELLigence system. Approximately $24 \mathrm{~h}$ after seeding the medium in the each well was discarded in order to get rid of the dead cells. When the cells were in the log growth phase, the cells were exposed to $100 \mu \mathrm{l}$ refresh DMEM containing the following substance: UDA $(1,5,10,20 \mu \mathrm{g} / \mathrm{ml})$. DMEM and $10 \%$ FBS were used as negative control group. All experiments were run for $48 \mathrm{~h}$. Cell index (CI) is derived to represent cell status based on the measured relative change in electrical impedance that occurs in the presence and absence of cells in the wells Impedance is measured at 3 different frequencies $(10,25$ or $50 \mathrm{kHz})$ and a specific time.

\section{TUNEL assay}

DNA fragmentation is an indicator for detecting the late apoptosis. TUNEL (Roche) is an assay that is composed of an enzyme solution and labeling solution which detects the nicks (single strand breaks) in DNA and binds to free 3'-OH ends. Adding of dUTPs to 3'-OH ends by terminal deoxynucleotidyl transferase cause labeling of DNA. Fluorescently labeled ends were detected by using confocal microscopy (Leica).AGS was used in this technique. The cell line was grown for TUNEL assay. AGS cells were seeded at $1 \times 10^{4}$ cells/well to the 96 well plates in final volume of $100 \mu \mathrm{l} /$ well culture medium in a humidified atmosphere $\left(37^{\circ} \mathrm{C}, 5 \% \mathrm{CO}_{2}\right)$ for $24 \mathrm{~h}$ before the treatment. Then the next day the highest concentration of UDA, $20 \mu \mathrm{M}$, was chosen for all of the cells. The cells were treated with $20 \mu \mathrm{g} / \mathrm{ml}$ UDA for $48 \mathrm{~h}$. Mitomycin $\mathrm{C}(10 \mu \mathrm{M})$ was used for the positive control. As a negative control (equivalent to normal viability) the cells were cultured without any substance in full medium.After the incubation period, the cells were washed twice with phosphate buffer solution (PBS), then fixed with 5\% paraformaldehyde for 60 minutes and washed again twice with PBST (PBS+0,1\% Triton-X-100) on the shaker. $0,1 \%$ Triton $\mathrm{X}$ were treated with $200 \mu \mathrm{L}$ with cells on the ice for 10 minutes. After that the cells were washed twice with PBST on shaker. TUNEL reaction mixture was added $50 \mu \mathrm{l}$ and incubated at $37^{\circ} \mathrm{C}$ in a humidified atmosphere with $0.5 \% \mathrm{CO}_{2}$ for an hour. After that the cells washed with PBST. And then DAPI (4',6-diamidino-2-phenylindole) is a fluorescent dye was applied on the cells for 15 minutes then washed once with PBST and once with distilled $\mathrm{H}_{2} \mathrm{O}$. The results were analyzed by fluorescence microscopy. 


\section{Binding on cell surface}

AGS cancer cell line waspassaged right after reaching desirable density in flasks. Passaged cells were seeded in 96 well-plate for each plate to be 10.000 cells. Plate was incubated for $24 \mathrm{~h}$ to provide the cell growth and attachment.After $24 \mathrm{~h}$ diluted fluorescent labeled lectin(EY Laboratories, USA) was applied on cell culture at $20 \mu \mathrm{g} /$ mlUDA concentration. After $24 \mathrm{~h}$ of incubation, cells were washed with buffer solution three times. Cells were examined with or without fixation under fluorescent microscope. Appropriate filter was used and FITCHabsorption was $492 \mathrm{~nm}$ and emission rate was $517 \mathrm{~nm}$.

\section{Statistical analysis}

The statistical analysis of WST-1 and LDH assay values MannWhitney U-test was used. Also for TUNEL assay values Chi-square $\left(\mathrm{X}^{2}\right)$ test was used. Statistical differences between time and dosage were analyzed. A value of P less than 0.05 was accepted as statistically significant. Results were expressed as mean \pm SE. For these procedures, SPSS 11.5 version for Windows (SPSS Inc, Chicago, Illinois, USA) was used. Cell Index calculations were obtained using the RTCA-integrated software of the xCELLigence system. The RTCA software performs a curve-fitting of selected "sigmoidal dose-response equation" to the experimental data points and calculates logarithmic half maximal inhibitory concentration $\left(\mathrm{IC}_{50}\right)$ values at a given time point based on $\log$ of concentration producing $50 \%$ reduction of $\mathrm{CI}$ value relative to solvent control CI value (100\%) in our results.

\section{Results}

\section{Effects of urticadioica agglutinin on AGS Cells}

Throughout 24th and 48th hours process of LDH assay, there was a significant effect of $U$. dioica agglutinin on AGS cells in which amount of LDH has increased. Namely, AGS cell which are exposed to LDH assay were ruptured. In other words, UDA has an effect on lipid peroxidation, either. On the other hand, WST-1 results showed that number of cells has decreased in all concentrations along with the treatment $(\mathrm{p}<0.05)$.

In another aspect, $\mathrm{x}$ CELLigence pointed out that as the concentration rises up, cell number goes down during both 24 and 48 hours. Also, there is clear difference between control and other concentrations (Figure 2A). The sigmoidal dose response curves of lectin tested in RTCA are shown in Figure 2B. All curves have an $r^{2}$ greater than or equal to 0.99 .

Considering TUNEL assay, positive control group and 20 $\mu \mathrm{g} / \mathrm{ml}$ concentration are statistically meaningful over negative control $(\mathrm{p}<0.05)$ (Figure 3). Hence, U. dioica agglutinin for $20 \mu \mathrm{g} /$ $\mathrm{ml}$ concentration along with 48th hours stated that cells ended up undergoing apoptosis. All indications together revealed that each assay compatible with theothers. Particularly, $20 \mu \mathrm{g} / \mathrm{ml}$ concentration was the most effective one in terms of cytotoxicity and apoptosis among all concentrations (Figure 4) $(\mathrm{p}<0.05)$.

In addition that, Figure 5 represents the $20 \mu \mathrm{g} / \mathrm{ml}$ concentration of FITC-UDA bound to carbohydrate residues in AGS cell membrane.

\section{Discussion}

A heterogeneous group of glyco-proteins having in common the unique ability to recognize and bind specific sugar residues is called to be plant lectins [11]. It is also noteworthy that lectins derived from nonimmune origin to have numerous links a wide range of pathological complicacies, most notably cancer [16]. Among these mistletoe lectins (MLs), Ricin, Concanavalin A (ConA) and Polygonatum cyrtonema lectin (PCL) can lead to cancer cell programmed death via targeting apoptotic pathways [17]. Moreover, ConA and PCL can also result in cancer cell programmed death. Possible anti-cancer therapeutic implications of plant lectins used as simple tumor recognition tools to differentiate malignant tumors from benign and the degree of glycosylation associated with metastasis [18]. Besides, other lectins such as ConA and PCL can result in cell death after internalization or binding certain sugar-containing receptors on the surface of cancer cells [19]. Plant lectins are thought to be decreasing expression of antiapoptotic nuclear factor-kB (NF-kB) [18]. Very recently it has been communicated that french bean hemagglutinin has been shown to induce breast cancer MCF-7 cell apoptosis [20]. Subsequently, lectins were found to bear remarkable inhibitory effects on the growth of

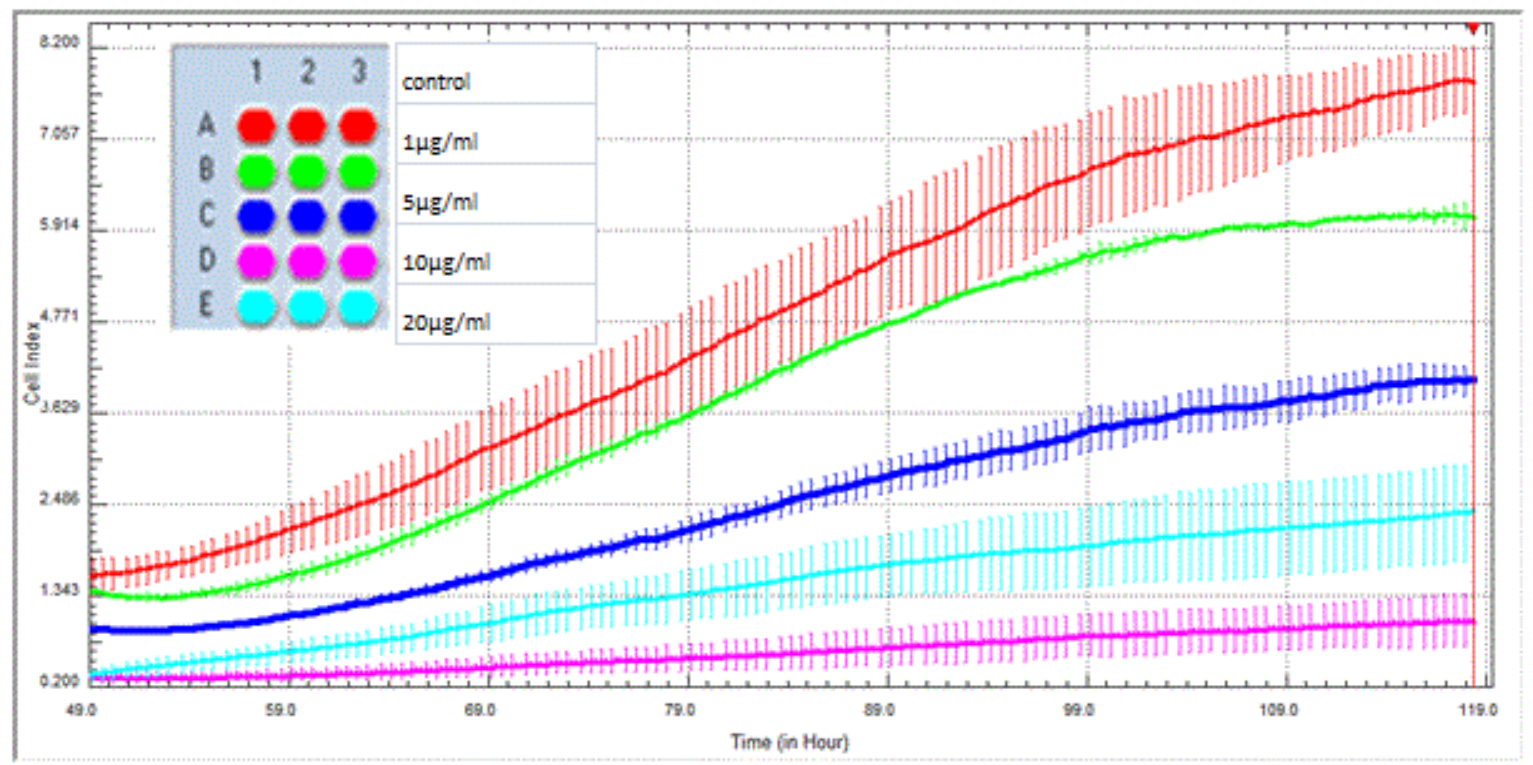

Figure 2A: Dynamic monitoring of lectin interaction with AGS cell line using the RTCA. 
Citation: Çagıl FZ, Akal ZU, Alpsoy L (2015) Cytotoxic and Apoptotic Effects of Urticadioica Agglutinin on AGS Cells. Med chem 5: 124-129. doi:10.4172/2161-0444.1000253
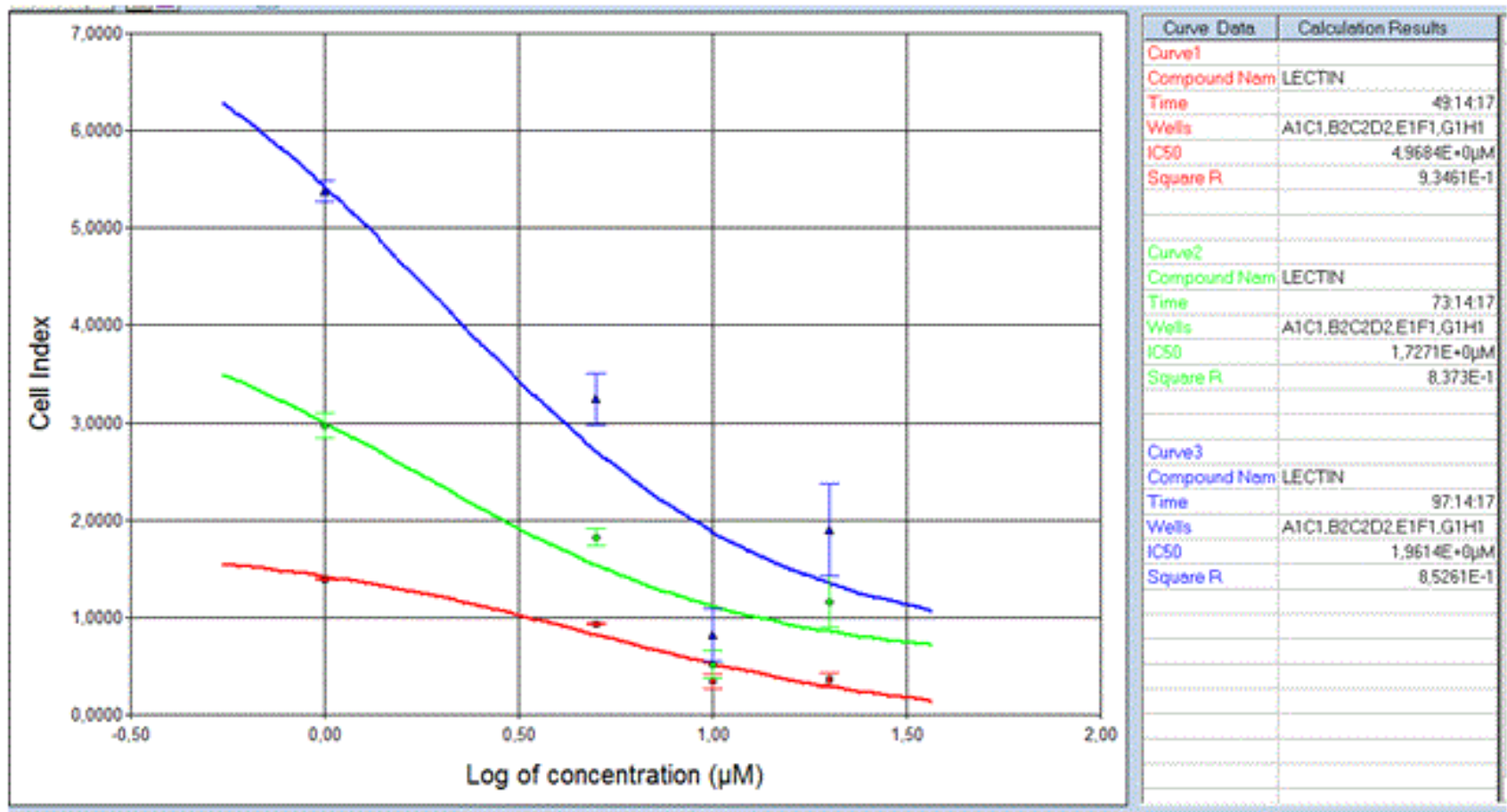

Figure 2B: IC50 value in RTCA system after 24, 48 and 72 hours treatment of lectin.

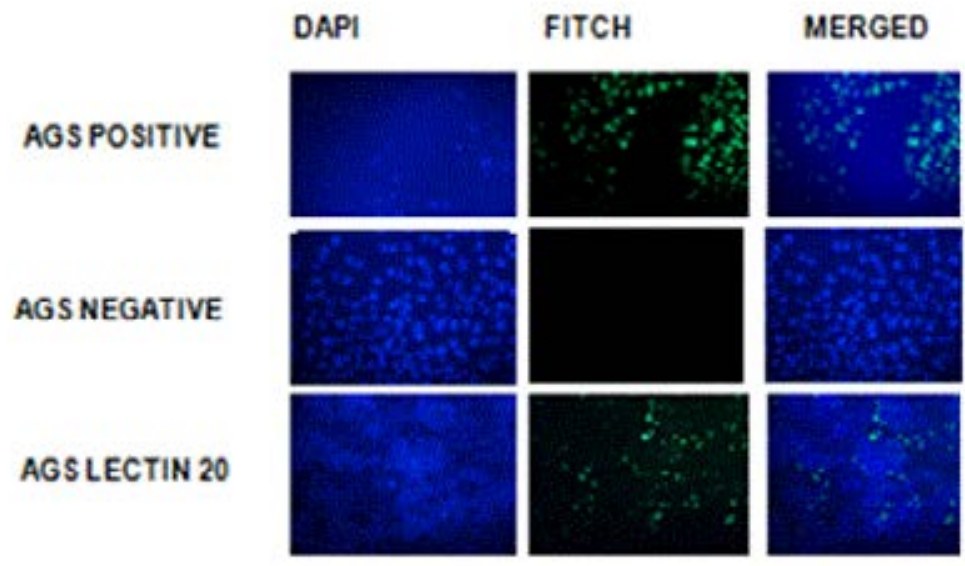

Figure 3: TUNEL assay fluorescence microscope image (10X). AGS NEGATIVE: AGS cell with medium (DMEM). AGS POSITIVE: AGS cell with Mitomycin C $(10 \mu \mathrm{M})$. AGS LECTIN 20: UDA $(20 \mu \mathrm{g} / \mathrm{ml})$ on AGS cell line.

MCF-7 and hepatoma HepG2 cells [21]. WGA treated cell at different concentrations $(0.5,1,2.5,5$ or $10 \mu \mathrm{M})$ for $24 \mathrm{~h}$ reduced cell viability of H3B, JAr and ROS cell lines [22]. In an effort to detect novel strategies in bladder cancer therapy, the potential and the applicability of different plant lectins was investigated using 5,637 cells as a model for human urinary carcinoma [23]. Specifically, the UDAis not blood group-specific and is specifically inhibited by $\mathrm{N}$-acetyl glucosamine oligomers [11]. Nevermore, UDA induces HuIFN-gamma in human lymphocytes at concentrations comparable to those of other inducers [11]. UDA is known having the ability to bind itself to the sugar residues on the cell surface [15].

UDA is first to be researched on cancer cell lines. In the light of previous studies, as a lectin form we thought that it would induce the inhibition of tumor growth in the way of the lectins in previous and recent studies. Accordingly, since the carbohydrate pattern of UDA is reflected by high abundance of $\mathrm{N}$-acetyl-D-glucosamine, we guessed that UDA would attach itself to cells through high carbohydrate content of cell membrane. In another saying, high binding rates, binding specificity would be advantageous for carbohydrate-mediated targeting in carcinoma therapeutics. In an effort to develop novel strategies for cancer therapy, at first the interaction of different concentrations of UDA was chosen. On the basis of former researches, we made a decision to pick the highest concentration as $20 \mu \mathrm{g} / \mathrm{ml}$.

We looked into cytotoxic, proliferative and apoptotic effects of UDA on AGS cell lines. This study points out that throughout 24 and $48 \mathrm{~h}$ of periods of time UDA decreased cell proliferation of AGS 
Citation: Çagıl FZ, Akal ZU, Alpsoy L (2015) Cytotoxic and Apoptotic Effects of Urticadioica Agglutinin on AGS Cells. Med chem 5: 124-129. doi:10.4172/2161-0444.1000253

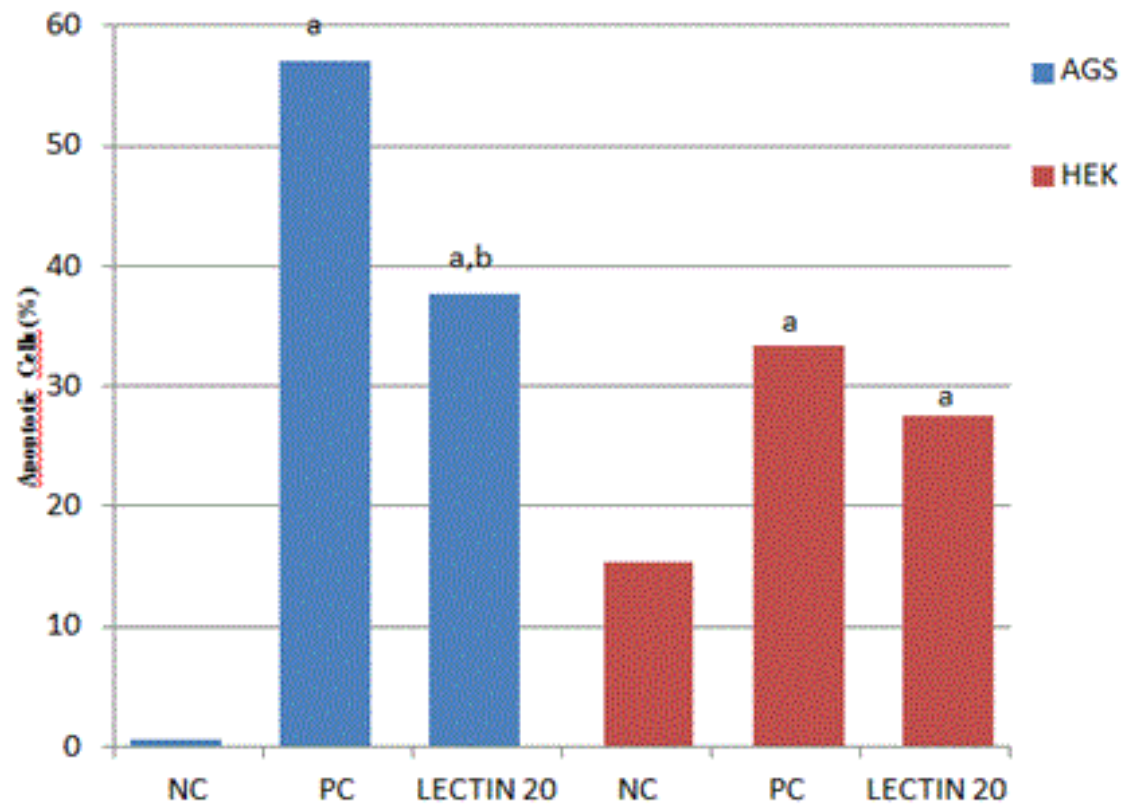

Figure 4: The results of TUNEL assay for UDA $(20 \mu \mathrm{g} / \mathrm{ml})$ on AGS cell line. ${ }^{\mathrm{a} p}<0.05$ compare with Negative Control, ${ }^{\mathrm{b} p}<0.05$ compare with Positive Control (Mitomycin C).

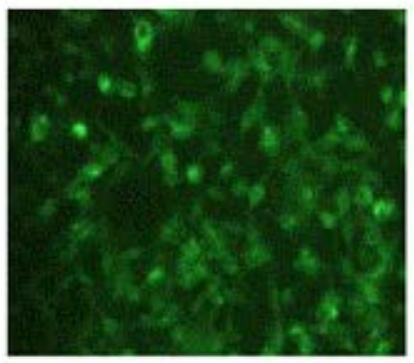

a

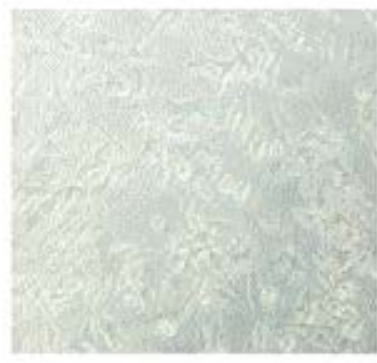

b

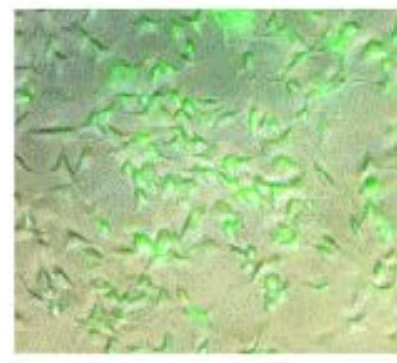

C

Figure 5: The Figure shows that the $20 \mu \mathrm{g} / \mathrm{ml}$ concentration of FITCH-UDA binds to AGS cell surface (10X). A) florescent microscopy image B) light microscopy image C) Merged image.

cell line at discrete concentrations. Number of viable cells was less in comparison to positive control group. In similar way, amount of lactate dehydrogenase enzyme increased along with both periods of time of 24 and 48 hours except for $20 \mu \mathrm{g} / \mathrm{ml}$ concentration. Namely we can interpret that manual assays conformed eachother at the time and dose dependent manner. According to xCELLigence results as the concentration goes up in density biological status of cells like cell number and viability decrease. At this point we thought that there might have been a complicacy or an experimental error between $10 \mu \mathrm{g} /$ $\mathrm{ml}$ and $20 \mu \mathrm{g} / \mathrm{ml}$ concentrations of AGS cell line during the process. Yet, in general we can conclude that for AGS cells as the concentration ascends, number of viable cells escalates. Last but not least, TUNEL results provided us percentage of DNA fragmentation on AGS cells at $20 \mu \mathrm{g} / \mathrm{ml}$ concentration. With the help of DNA fragmentation percent we became able to say that apoptosis is statistically significant. Which collectively means that UDA especially at the highest concentration likely to have cytotoxic effect on AGS cell line. Our study indicates that cell proliferation reduced number of viable cells at the time basis and increasing concentrations.Finally, binding ability of UDA was searched in this study, either. And FITCH Conjugated Lectin provided us UDA has the feature of binding itself to sugar moieties on the cell surfaces. It can be said that the surface binding tendency of UDA have been shown.

In literature there is no study about anti-proliferative effects of UDA on AGS cell line. In short, UDA has anti-proliferative and apoptotic effects on AGS cell line. UDA decreases cell proliferation and increases apoptosis in AGS cell line.

\section{Conclusion}

In this research, we evaluated the updated research of one of the good representative plant lectins that may lead to programmed cell death via targeting apoptotic and cytotoxic pathways in different types of cancer cells. In conclusion, UDA at different concentrations has anti-proliferative and apoptotic effects on AGS cell line. Moreover lowest concentration of UDA, effects AGS cells in cytotoxic manner. Also, this study has the unique feature of being studied with FITCHlabeled lectin. 
Citation: Çagıl FZ, Akal ZU, Alpsoy L (2015) Cytotoxic and Apoptotic Effects of Urticadioica Agglutinin on AGS Cells. Med chem 5: 124-129. doi:10.4172/2161-0444.1000253

\section{Acknowledgement}

The authors are thankful to the Fatih University, Research Project Foundation (Contract no: P50031301_B (2923) for financial support of this study.

\section{References}

1. Akgul A (1993) Spies Science and Technology. Association Food Technology 15.

2. Borchers AT, Keen CL, Stern JS, Gershwin ME (2000) Inflammation and Native American medicine: the role of botanicals.Am J ClinNutr 72: 339-347.

3. Gulcin I,Kufrevioglu OI, Oktay M, Buyukokuroglu ME (2004) Antioxidant antimicrobial, antiulcer and analgesic activities of nettle (Urticadioica L.).J Ethnopharmacol 90: 205-215

4. Kultur S (2008) Anethnobotanical study of Kırklareli (Turkey). Phytologiabalcanica 14: 279-289.

5. Avci G,Kupeli E, Eryavuz A, Yesilada E, Kucukkurt I (2006) Antihypercholesterolaemic and antioxidant activity assessment of some plants used as remedy in Turkish folk medicine. J Ethnopharmacol 107: 418-423.

6. Chrubasik JE,Roufogalis BD, Wagner H, Chrubasik S (2007) A comprehensive review on the stinging nettle effect and efficacy profiles. Part II: urticae radix. Phytomedicine 14: 568-579.

7. Mahmoud $\mathrm{AH}$ (2006) Changes in Proteins, Total Lipids and Phospholipids in Mice Liver Treated with Urticapilulifera Extracts. Asian Journal of Biochemistry 8.

8. Rispail N, Morris P, Webb KJ (2005) Phenolic compounds extraction and analysis. Lotus japonicus Handbook 349-354.

9. Ganzera M, Piereder D, Sturm S, Erdelmeier C, StuppnerH (2005)Urticadioica agglutinin: separation, identification, and quantitation of individual isolectins by capillary electrophoresis and capillary electrophoresis-mass spectrometry. Electrophoresis 26: 1724-1731.

10. Van Damme EJM, Peumans WJ, Pusztai A, Bardocz S (1998) Handbook of plant lectins: properties and biomedical applications. Chichester: John Wiley and Sons.

11. Peumans WJ, Ley MD, Broekaert WF (1984)An unusual lectin from stinging nettle (Urticadioica) Rhizomes. FEBS Letter 177: 99-103.
12. Shibuya N, Goldstein IJ, Shafer JA, Peumans WJ, Broekaert WF (1986) Carbohydrate binding properties of the stinging nettle (Urticadioica) rhizome lectin.Arch BiochemBiophys 249: 215-224.

13. Saul FA,Rovira P, Boulot G, Damme EJ, Peumans WJ, et al. (2000) Crysta structure of Urticadioica agglutinin, a superantigen presented by $\mathrm{MHC}$ molecules of class I and class II.Structure 8: 593-603.

14. Le Moal MA, Colle JH, Galelli A, Truffa-Cachi P (1992b) Mouse T-lymphocyte activation by Urticadioica agglutinin: II.â€" original pattern of cell activation and cytokine production induced by UDA. Res Immunology 143: 701-709.

15. Le Moal MA,Truffa-Bachi $P$ (1988) Urticadioica agglutinin, a new mitogen for murine $T$ lymphocytes: unaltered interleukin-1 production but late interleukin 2-mediated proliferation.Cell Immunol 115: 24-35.

16. Ghazarian H,Idoni B, Oppenheimer SB (2011) Aglycobiology review: carbohydrates, lectins and implications in cancer therapeutics.ActaHistochem 113: 236-247.

17. Thies A, Nugel D, Pfuller U, Moll I, Schumacher U (2005) Influence of mistletoe lectins and cytokines induced by them on cell proliferation of human melanoma cells in vitro. Toxicology 207: 105-116.

18. Fu LL, Zhou CC, Yao S, Yu JY, Liu B, et al. (2011) Plant lectins: targeting programmed cell death pathways as antitumor agents. Int J Biochem Cell Bio 43: $1442-1449$.

19. Lei HY, Chang CP (2009) Lectin of Concanavalin A as an anti-hepatoma therapeutic agent.J Biomed Sci 16: 10.

20. Lam SK, Ng TB (2011) Lectins: production and practical applications. Appl Microbiol Biotechnol 89: 45-55.

21. Liu B,Bian HJ, Bao JK (2010) Plant lectins: potential antineoplastic drugs from bench to clinic. Cancer Lett 287: 1-12.

22. Wang H, Ng TB, Ooi VE, Liu WK (2000) Effects of lectins with different carbohydrate-binding specificities on hepatoma, choriocarcinoma, melanoma and osteosarcoma cell lines.Int J Biochem Cell Biol 32: 365-372.

23. Plattner VE, Wagner M, Ratzinger G, Gabor F, Wirth M (2008) Targeted drug delivery: binding and uptake of plant lectins using human 5637 bladder cancer cells.Eur J Pharm Biopharm 70: 572-576. 